\title{
Expression of e-NOS in Human Placentas of Idiopathic Intra Uterine Growth Restriction at Term
}

\author{
Mohammed E. Ghanem ${ }^{1}$, Samia A. Eleiwe ${ }^{2}$ \\ ${ }^{1}$ Department of Anatomy, Histology \& Embryology, ${ }^{2}$ Asst. Lect. Dr. Faculty of College of Medicine, Al- Kindy \\ College of Medicine, Baghdad University, Baghdad, Iraq
}

\begin{abstract}
Endothelial nitric oxide synthase (e-NOS) is a chemical agent that involves in placental angiogenesis. It is conveyed through embryogenesis. In the contemporary study, we intended to examine the character of placental angiogenesis in the progress of intrauterine growth restriction (IUGR) by means of matching the levels of expression of e-NOS in normal-term pregnancy and IUGR placentas. Angiogenesis is one dominant factor in normal embryogenesis and hence the wellbeing of the newborn. The expression of e-NOS was planned using the streptavidin-biotin-peroxidase technique in placental tissues identified as normal $(\mathrm{n}=33)$ and IUGR $(\mathrm{n}=33)$ cases from mothers looking apparently normal. All were chosen at term pregnancy and obtained between $2^{\text {nd }}$ of February of 2018 and $31^{\text {th }}$ of January 2019 at selected hospitals. Outcomes were appraised semi-quantitatively. The expression of e-NOS marker as an immunohistochemistry total score and staining percentage were significantly greater $(p<0.05)$ in epithelial surface, smooth muscle cells of fetal vessels and the connective tissue terminal villous core of the IUGR placentas when matched with placentas collected from normal pregnancies at term. Encountered placental histochemical changes regarding the expression of the e-NOS angiogenic factor for idiopathic IUGR newborns raised the suspicion of that, it was caused by pure placental factors and could represent further requirement for Nitric Oxide to dilate fetal vessels to optimize functional requirement during placental insufficiency. The noticed Increased expression of e-NOS may be the result of inadequate uteroplacental perfusion supporting the proposal that abnormal angiogenesis plays a role in the pathophysiology of IUGR.
\end{abstract}

Keywords: Idiopathic Iugr, E-Nos, Placenta, Terminal Villi, Immunohistochemistry.

\section{Introduction}

Intrauterine growth restriction/retardation (IUGR) is a complex placental vascular disorder resulting in limited weight at birth, preterm delivery, with highly expected perinatal morbidity and mortality ${ }^{1-4}$. IUGR could be triggered by different fetal, maternal, and placental influences ${ }^{1-3,5}$. Angiogenesis is regarded as a placental factor acting essentially in the development of IUGR $2-4,6,7$. Angiogenesis involves the branching of new microvessels from present larger blood vessels. It is an imperative aspect in normal embryogenesis ${ }^{8-10}$. Angiogenesis affects greatly the development of the villous vascular tree and the development of chorionic terminal villi. Placental vascular branching early in embryonic life and continues all over gestation 9,11. Precise angiogenesis up regulators and down regulators adjust this processe $4,8,9$. Fetal growth restriction happens because of the failure of elongation, branching, or dilitation of the capillary circulation of terminal villi ${ }^{4}$. e-NOS has been acknowledged as stimulator for angiogenesis ${ }^{8}$. It is highly expressed throughout embryogenesis and fetal development 1,6,10,12. It synthesizes nitric oxide (NO) solely in the placenta ${ }^{13,14}$, signifying that e-NOS is in charge for the increased NO in the placenta. e-NOS is chiefly accountable for the propagation of $\mathrm{NO}$ in the vascular endothelial layer of fetal vessels in the placenta ${ }^{15,16}{ }^{17}$. The e-NOS-derived NO is likewise a strong vasodilator compound in the perfused feto-placental vasculature which is empowered by smooth muscles ${ }^{18}$, that is essential for the upkeep of decreased resistance at the fetoplacental interface ${ }^{19}$. Initial revisions have demonstrated that drug conveyed e-NOS suppression results in signs resembling preeclampsia and growth restricted fetuses in rats ${ }^{20-25}$.

Patients and Methods: This work was carried out through Department of Anatomy, Medical Faculty, 
University of Al-Mustansiriyah, in assistance of Gynecology and Obstetrics department at Fatima AlZahraa Administrative Hospital, Al- Khadhraa Private Hospital and Al- Yarmook Teaching Hospital in Baghdad, Iraq. Permitted by the scientific committee of each of these medical institutes. A total of 66 mothers, along with their newborns and placentas were incorporated in this study. All were chosen at term pregnancy (of 38-40 weeks), they were non-smoker, nondiabetic, normotensive apparently healthy and normal women according to their history, clinical assessments, laboratory tests and ultrasound check. Fetal state as IUGR likewise was verified by Doppler ultrasonic exam without apparent fetal anomalies. Any mother suffered from difficult or delayed labor been ruled out from this work. A consent was gained verbally from each mother to be a component of this work. All fetal IUGR was considered to be idiopathic, given that there were no apparent maternal nor fetal basis. Placentas were assigned into two groups. The 1 st embraced 33 placentas of newborns having normal average body weight (Control), whereas the 2nd group holds 33 placentas of newborns having idiopathic IUGR based on the basis of a valued fetal weight of less than the gestational tenth percentile, decreased amnion, and proved diminshed end diastolic flow velocity of the umbilical artery by Doppler study confirmed by successive obstetric ultrasound examination ${ }^{26}$. Every tissue block measured roughly $1 \times 1 \times 1$ centimeter to be fixed to be stained by Immunohistochemistry e-NOS marker. Then, from every tissue block five sequential sections of about 4 $\mu \mathrm{m}$ thicknesses were obtained and were collected on positive charged slides. After de-waxing, the sections were rehydrated gradually. Immunohistochemical staining achieved by the avidin-biotin-peroxidase technique. $3 \%$ hydrogen peroxide blocking agent was used to block Endogenous peroxidase. Kept in oven for 15 minutes in sodium citrate buffer solution $(\mathrm{pH}=6.0)$ for antigen retrieval. Rabbit polyclonal antibodies reactive with e-NOS (Abnova) was added to the sections and incubated for one hour at room temperature. Sections were washed with phosphate-buffered saline with Tween, then a secondary antibody added for 20 minutes and after that with a biotin-streptavidin complex for half an hour at room temperature. 3,3-diaminobenzidine tetrahydrochloride (DAB) was used to visualize reaction. Finally, the sections were counterstained with hematoxylin and mounted. The intensity and localization of the staining reaction in Syncytiotrophoblasts (epithelial cells), vascular smooth muscle cells (vessels) and chorionic villous stromal connective tissue cells (C.T.) were calculated by two pathologists blinded to the drive of the study. Immunohistochemical reaction of e-NOS antibody scored semiquantitatively for intensity of staining: $0 /$ negative $=$ no staining, $1+=$ weak positive, $2+=$ moderately positive; $3+$ strongly positive. The total score of immunohistochemistry staining obtained from multiplying the staining intensity with staining percentage for each region in high power field. Statistical analysis achieved by using SPSS v24. Continuous variables were illustrated as mean \pm SD and the categorical variables were demonstrated in percentages. Chi-square test was used to compare groups for immunohistochemical outcomes. P - values $<0.05$ were considered statistically significant.

\section{Results}

e-NOS immunohistochemistry cytoplasmic staining was perceived from both control and idiopathic IUGR tissues (Table 1, and Figures 1,2 and 3). A highly significant increase in the expression of e-NOS in IUGR placentas seen in syncytiotrophoblasts (epithelial cells) when compared to control group with $p$ value $=0.003$, Also, increase in staining percentage in the IUGR group but no statistical significance with $p$ value $=0.077$ difference when compared to the control groups. Regardless, the total score of e-NOS marker in epithelium was significantly higher in IUGR group than that in control groups $(p=0.004)$. regarding the fetal vessels, the staining intensities of e-NOS marker were significantly higher in IUGR group with $\mathrm{p}$ value $=0.02$ when compared to the control group. Staining percentage of e-NOS marker in vessels was also significantly higher in IUGR group than that in control groups with $p$ value $=0.016$. The foregone total score of e-NOS marker in vessels was significantly higher in IUGR group than that in control groups with $\mathrm{p}=0.011$. Regarding the expression of e-NOS in the connective tissue of the villus core of terminal chorionic villi revealed statistically significant increase in intensity in IUGR group when compared to the control group with $\mathrm{p}$ value $=0.001$. The staining percentage was also significantly higher $(\mathrm{p}=0.001)$ and the staining score is also significantly higher in IUGR when compared to control group ( $\mathrm{p}=0.007)$. 


\section{Difference in staining intensity between IUGR \& Control tissues *}

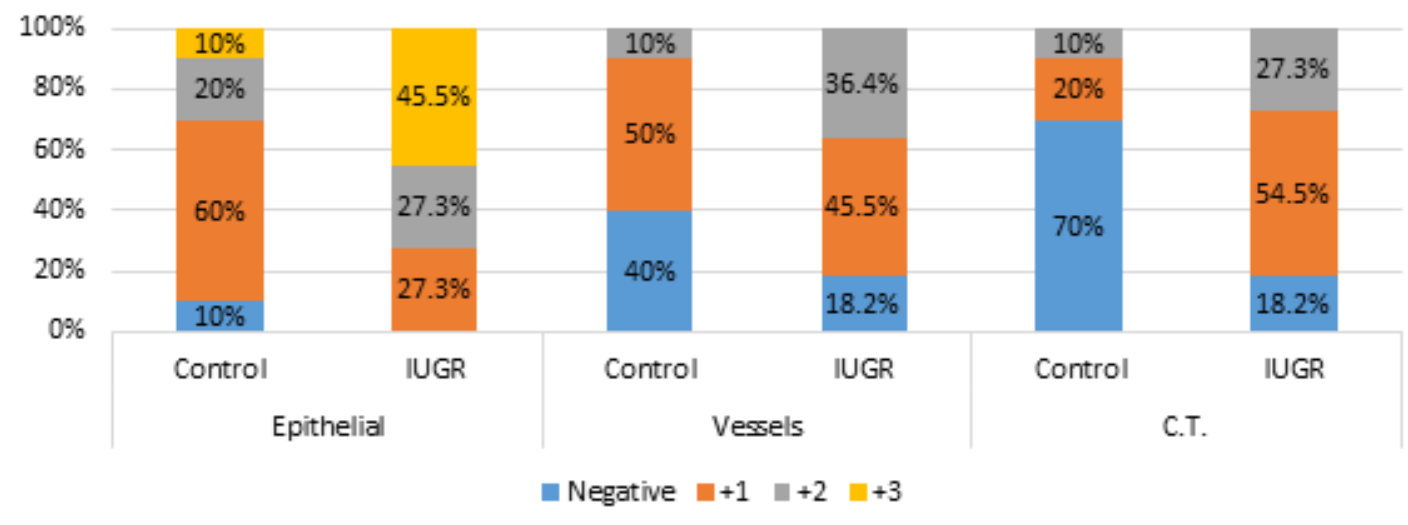

Figure (1): Difference in staining intensity of e-NOS between IUGR \& Control tissues $(* \mathrm{p}$ value $<0.05)$

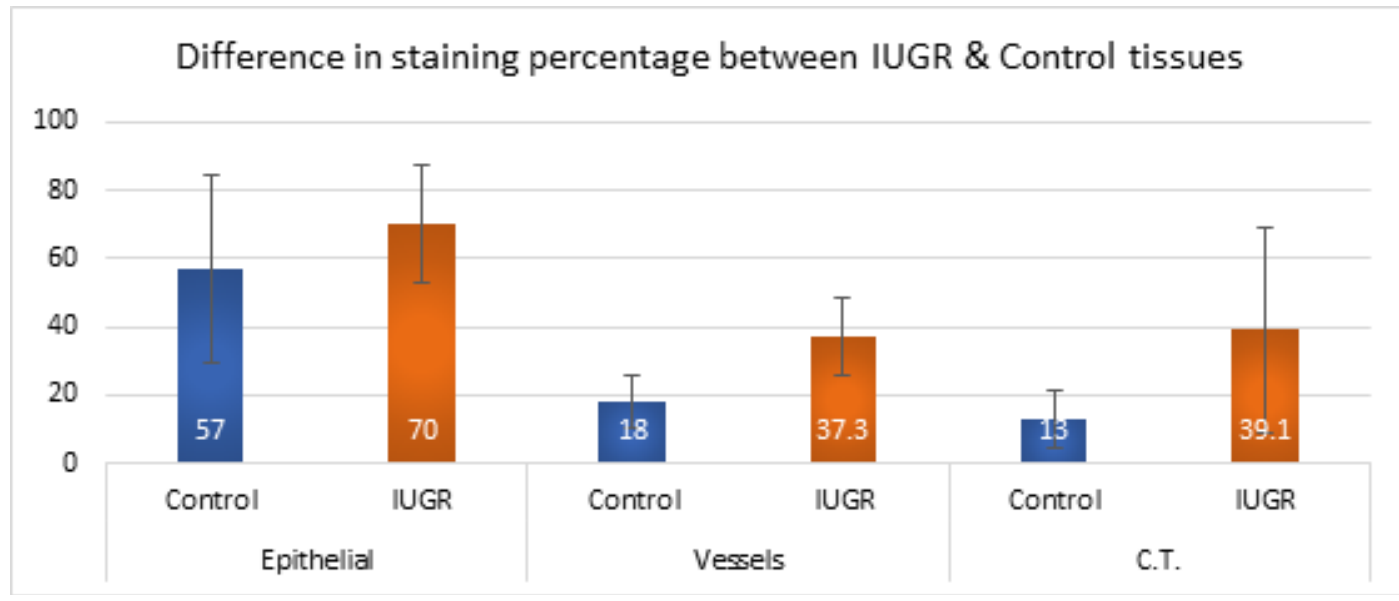

Figure (2): Difference in staining percentage of e-NOS between IUGR \& Control tissues.

Table (1): Difference in staining total score of e-NOS between IUGR \& Control tissues.

\begin{tabular}{|l|l|l|l|l|}
\hline localization & & Mean & Std. Deviation & p Value \\
\hline \multirow{2}{*}{ Epithelial } & Control & 1.0 & \pm 0.82 & 0.004 \\
\hline \multirow{2}{*}{ Vessels } & IUGR & 1.62 & \pm 0.86 & 0.011 \\
\hline \multirow{2}{*}{ C.T. } & Control & 0.27 & \pm 0.5 & \pm 0.62 \\
\cline { 2 - 4 } & IUGR & 0.61 & \pm 0.51 & 0.007 \\
\hline
\end{tabular}

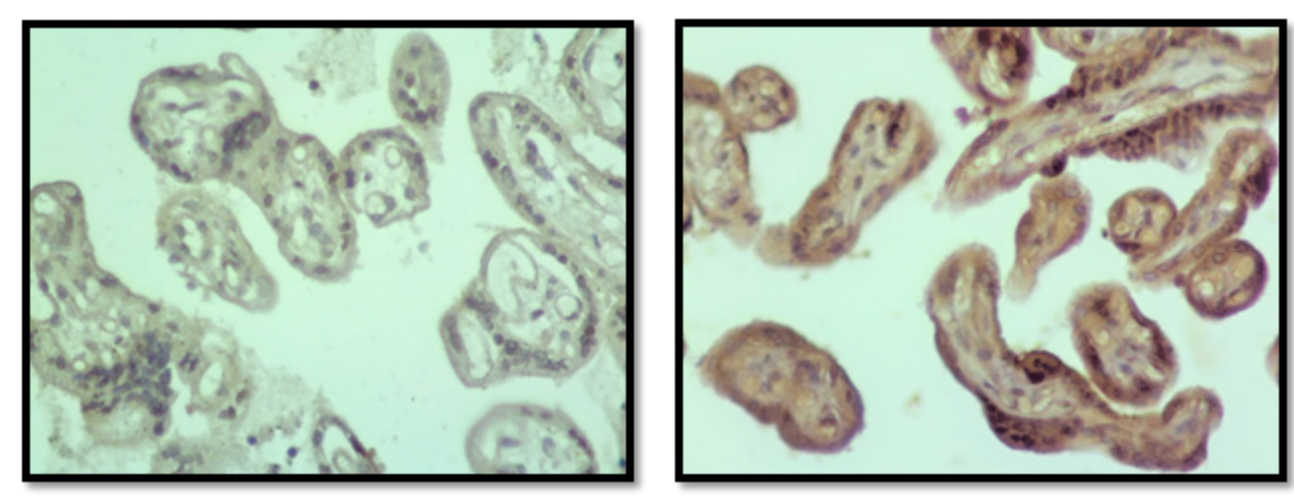

Figure (3): e-NOS staining reaction expressed in terminal villi of placenta, A; showing weak e-NOS staining in control group, B; showing e-NOS stronger expression in idiopathic IUGR group (DAB, A; B; × 400). 


\section{Discussion}

Many previous studies had documented that a pure placental factor was the solitary cause in some IUGR cases ${ }^{27}$. IUGR incidence was noticed 3\% regarding developed countries, though, it scopes $15-20 \%$ in developing countries, it partakes in more than $26 \%$ stillbirths and congenital anomaly 1,4,5. Not to forget it yields many lasting health issues for grownups ${ }^{28}$. Therefore, the precise diagnosis, and proper management of IUGR-complicated pregnancies are important. Regarding e-NOS expression in the epithelial cells, our results differ from the study of Myatt et al (1997) 29 as they had found no differences in the intensity or type of staining. Regarding the fetal vessels, our results agree with Myatt et al (1997) ${ }^{29}$ and Rutherford and colleagues $(1995)^{30}$. However, other authors have found decreased levels of e-NOS in vessels in these condition like Giannubilo et al. $(2008)^{31}$ and Noris et al. (2004) ${ }^{32}$. We hypothesize that the increased e-NOS expression in their vessels is not a disease-specific feature, but perhaps an adaptive response to increased resistance and poor perfusion. It seemed to be no previous works measured the expression of e-NOS in the villus core of terminal chorionic villi of term placenta neither in normal nor in pathological cases like IUGR. The significant elevation in expression of this enzyme, e-NOS, in this region particularly could be explained by its rapid diffusion from endothelial cells to the core, it had been found that it down regulates fibroblast production to decrease villus fibrosis decreasing the fibroblastic activity ${ }^{33}$ which in turn reducing the density of the villus core to enhance feto-maternal exchange. It is possible that increased expression of e-NOS seen in our results in idiopathic IUGR placentas at term in all mentioned regions impinge upon regulation of placental vascular reactivity by the smooth muscle of fetal vessels and hence blood flow regulation. In support of this, it had been shown that concentrations of nitrate, a breakdown product of NO, were significantly higher at delivery in umbilical venous blood from idiopathic IUGR pregnancies compared with controls ${ }^{34}$. The observed increased expression of e-NOS that we saw in placentas of Idiopathic IUGR could encourage pathological angiogenesis ${ }^{35}$.

\section{Conclusion}

Toward elucidate the pathogenesis of idiopathic IUGR and the associated placental vascular insufficiency, it is needed to clarify the regulatory mechanism of placental vascular development. The noted increased staining expression of e-NOS designates pathological angiogenic action, due to lacking proper uteroplacental perfusion, resulting in the formation of idiopathic IUGR.

Ethical Clearance: was approved and granted from Al-Mustansiryia University, Al-Rusafa and Al-Karkh health Directorate application forms as a requirement to obtain $\mathrm{PhD}$ degree in Anatomy, Histology and Embryology. Research projects are reviewed and conducted ethically. This research is not published yet.

Source of Funding: This study was self-funded.

Acknowledgment: I would like to express my truthful gratefulness to my supervisor Dr. Samia A. Eleiwe for her generous assistance, grate support and continuous wise guidance throughout the course of this study. I am grateful to Dr. Ahmed Fakhir Hameed for always taking the time to help me, and patiently assisting me with my work.

\section{Conflict of Interest: Nil}

\section{References}

1- Gurel D, Özer E, Altunyurt S, Guclu S, Demir N: Expression of IGR-IR and VEGF and trophoblastic proliferative activity in placentas from pregnancies complicated by IUGR. Pathol Res Pract 2003; 199:803-809.

2- Maulik D, Evans JF, Ragolia L: Fetal growth restriction: Pathogenic mechanisms. Clin Obstet Gynecol 2006; 49:219-227.

3- Arroyo JA, Winn VD: Vasculogenesis and angiogenesis in the IUGR placenta. Semin Perinatol 2008; 32:172-177.

4- Ahmed A, Perkins J: Angiogenesis and intrauterine growth restriction. Baillieres Best Pract Res Clin Obstet Gynaecol 2000; 14:981-998.

5- Ozkan S, Vural B, Dalçık C, Tas, A, Dalçık H: Placental expression of insulinlike growth factor-I, fibroblast growth factor-basic and neural cell adhesion molecule in pregnancies with small for gestational age fetuses. J Perinatol 2008; 28:468474.

6- Shiraishi S, Nakagawa K, Kinukawa N, Nakano $\mathrm{H}$, Sueishi K: Immunuhistochemical localization of vascular endothelial growth factor in the human placenta. Placenta 1996; 17:111-121.

7- Pardi G, Marconi AM, Cetin I: Pathophysiology of intrauterine growth retardation: role of the placenta. 
Acta Paediatr 1997; 423(Suppl):170-172.

8- Frater JL, Kay NE, Goolsby CL, Crawford SE, Dewald GW, Peterson LC: Dysregulated angiogenesis in B-chronic lymphocytic leukemia: Morphologic, immunohistochemical, and flow cytometric evidence. Diagn Pathol 2008; 3:16.

9- Kaufmann P, Mayhew TM, Charnock-Jones DS: Aspects of human fetoplacental vasculogenesis and angiogenesis. II. Changes during normal pregnancy. Placenta 2004; 25:114-126.

10- Lee MY, Huang JP, Chen YY, Aplin JD, Wu YH, Chen CY, Chen PC, Chen CP: Angiogenesis in differentiated placental multipotent mesenchymal stromal cells is dependent on integrin alpha5beta1. PLoS One 2009; 4:e6913.

11- Nakagawa Y, Fujimoto J, Tamaya T: Placental growth by the estrogen dependent angiogenic factors, vascular endothelial growth factor and basic fibroblast growth factor, throughout gestation. Gynecol Endocrinol 2004; 19:259-266.

12- Marsden PA, Schappert KT, Chen HS, Flowers M, Sundell CL, Wilcox JN, Lamas S, Michel T. "Molecular cloning and characterization of human endothelial nitric oxide synthase". FEBS Lett. 1992; 307 (3): 287-93.

13- Hamai Y, Fujli T, Yamashita T, Kozuma S, Okai T, Taketani Y: Evidence for basic fibroblast growth factor as a crucial angiogenic growth factor, released from human trophoblasts during early gestation. Placenta 1998; 19:149-155.

14- Myatt L, Eis ALW, Brockman DE, Greer IA, Lyall F: Endothelial nitric oxide synthase in placental villous tissue from normal, pre-eclamptic and intrauterine growth restricted pregnancies. Hum Reprod 1997; 12:167-172.

15- Cockcroft JR. "Exploring vascular benefits of endothelium-derived nitric oxide". American Journal of Hypertension. 2005; 18 (12 Pt 2): $177 \mathrm{~S}-183 \mathrm{~S}$.

16- Villanueva C, Giulivi C. "Subcellular and cellular locations of nitric oxide synthase isoforms as determinants of health and disease". Free Radical Biology \& Medicine. 2010; 49 (3): 307-16.

17- Sumpio BE, Riley JT, Dardik A. "Cells in focus: endothelial cell". The International Journal of Biochemistry \& Cell Biology. 2002; 34 (12): 150812.
18- Myatt L, Brewer AS, Langdon G, Brockman DE. Attenuation of the vasoconstrictor effects of thromboxane and endothelin by nitric oxide in the human fetal-placental circulation. Am J Obstet Gynecol. 1992; 166: 224-230.

19- Chang JK, Roman C, Heymann MA. Effect of endothelium-derived relaxing factor inhibition on the umbilical-placental circulation in fetal lambs in utero. Am J Obstet Gynecol 1992; 166: 727-734.

20- Buhimschi I, Yallampalli C, Chwalisz K, Garfield RE. Pre-eclampsia-like conditions produced by nitric oxide inhibition: effects of L-arginine, D-arginine and steroid hormones. Hum Reprod. 1995; 10: 2723-2730.

21- Kusinski LC, Stanley JL, Dilworth MR, Hirt CJ, Andersson IJ, Renshall LJ, Baker BC, Baker PN, Sibley CP, Wareing M, Glazier JD. eNOS knockout mouse as a model of fetal growth restriction with an impaired uterine artery function and placental transport phenotype. Am J Physiol Regul Integr Comp Physiol. 2012; 303: R86-R93.

22- Kulandavelu S, Whiteley KJ, Bainbridge SA, Qu D, Adamson SL. Endothelial NO synthase augments fetoplacental blood flow, placental vascularization, and fetal growth in mice. Hypertension. 2012; 61: 259- 266.

23- Kusinski LC, Stanley JL, Dilworth MR, Hirt CJ, Andersson IJ, Renshall LJ, Baker BC, Baker PN, Sibley CP, Wareing M, Glazier JD. eNOS knockout mouse as a model of fetal growth restriction with an impaired uterine artery function and placental transport phenotype. Am J Physiol Regul Integr Comp Physiol. 2012; 303: R86-R93.

24- Van der Heijden OW, Essers YP, Fazzi G, Peeters LL, De Mey JG, van Eys GJ. Uterine artery remodeling and reproductive performance are impaired in endothelial nitric oxide synthasedeficient mice. Biol Reprod. 2005; 72: 1161-1168.

25- Kulandavelu S, Whiteley KJ, Qu D, Mu J, Bainbridge SA, Adamson SL. Endothelial nitric oxide synthase deficiency reduces uterine blood flow, spiral artery elongation, and placental oxygenation in pregnant mice. Hypertension. 2012; 60: 231-238.

26- Galan HL, Pandipati S, Filly RA: Ultrasound evaluation of fetal biometry and normal and abnormal fetal growth. In Ultrasonography in obstetrics and gynecology 5th edition. Edited by: 
Callen PW. USA: Saunders Elsevier. 2008; 225265.

27- Guttmacher AE, Maddox YT,Spong CY. The Human Placenta Project: Placental Structure, Development, and Function in Real Time. Placenta. $2014,35(5): 303-4$.

28- Kinzler WL, Vintzileos AM: Fetal growth restriction. Curr Opin Obstet Gynecol 2008; 2:125131.

29- L.Myatt, A.L.W.Eis, D.E. Brockman, I.A.Greerand F.Lyall Endothelial nitric oxide synthase in placental villous tissue from normal, pre-eclamptic and intrauterine growth restricted pregnancies Human Reproduction 1997. vol.12 no.1 pp.167172.

30- Rutherford R.A., McCarthy A., Sullivan M.H., Elder M.G., Polak J.M., Wharton J. Nitric oxide synthase in human placenta and umbilical cord from normal, intrauterine growth-retarded and pre-eclamptic pregnancies. $\mathrm{Br} \mathrm{J}$ Pharmacol. 1995;116:3099-3109.
31- Giannubilo S.R., Menegazzi M., Tedeschi E., Bezzeccheri V., Suzuki H., Tranquilli A.L. Doppler analysis and placental nitric oxide synthase expression during fetal growth restriction. J Matern Fetal Neonatal Med. 2008; 21:617-622.

32- Noris M., Todeschini M., Cassis P., Pasta F., Cappellini A., Bonazzola S. L-arginine depletion in preeclampsia orients nitric oxide synthase toward oxidant species. Hypertension. 2004;43:614-622.

33- Annette Keil, Ingrid E.Blom, Roel Goldschmeding, Harald D.Rupprecht. Nitric oxide down-regulates connective tissue growth factor in rat mesangial cells Kidney International Volume 62, Issue 2, August 2002, Pages 401-411

34- Lyall, F., Greer, I.A., Young, A. and Myatt, L. (1996) Nitric oxide concentrations are increased in the feto-maternal circulation in intrauterine growth restriction. Placenta, 17, 165-168.

35- Simpson L, Khati NJ, Deshmukh SP, et al. ACR Appropriateness Criteria Assessment of Fetal WellBeing. J Am Coll Radiol 2016; 13:1483. 